\title{
A EVOLUÇÃO DA CARREIRA DE MAGISTÉRIO DE ENSINO BÁSICO, TÉCNICO E TECNOLÓGICO (EBTT) NOS INSTITUTOS FEDERAIS
}

\author{
D. S. BRITO ${ }^{1^{*}}$ e F. S. CALDAS ${ }^{2}$ \\ ${ }^{1}$ Instituto Federal de Educação, Ciência e Tecnologia do Maranhão - IFMA \\ ${ }^{2}$ Universidade Estadual do Piauí - UESPI \\ deusbrito@ifma.edu.br*
}

Artigo submetido em janeiro/2016 e aceito em maio/2016

DOI: $10.15628 /$ rbept.2016.4024

\section{RESUMO}

Neste artigo se propõe discorrer sobre a evolução e as mudanças ocorridas na carreira de Magistério do Ensino Básico, Técnico e Tecnológico (EBTT) fazendo um viés pela educação profissional brasileira desde sua implantação até as mudanças ocorridas mais recentemente. Neste estudo procurou-se buscar o nexo entre as instituições existentes anteriormente e a criação da nova instituição, que se materializou nos Institutos Federais de Educação, Ciência e Tecnologia, denominadas atualmente somente de Institutos Federais, criados no bojo da Reforma da Educação Profissional pela Lei 11.892/2008, mesma lei que redesenhou a rede federal de educação profissional, então existente no Brasil. O presente trabalho trata-se de uma pesquisa bibliográfica, que objetiva o registro da evolução histórica a respeito da criação da carreira de magistério do EBTT e da atual reforma da educação profissional.

PALAVRAS-CHAVE: Magistério EBTT, Magistério Superior, Rede Ensino Profissional.

\section{THE EVOLUTION OF BASIC EDUCATION OF TEACHING CAREER, TECHNICAL AND TECHNOLOGICAL (EBTT) IN FEDERAL INSTITUTES}

\begin{abstract}
In this paper proposes to discuss the evolution and changes in the magisterium career of Basic Education, Technical and Technological (BETT) making a lateral study in relation brazilian professional education since its implementation going through changes recent. In this study we tried to make an link between the pre-existing institutions and the creation of the new institution, which materialized in the Federal Institutes of Education, Science and Technology, currently known only of Federal
\end{abstract}

Institutes, created by the reform of Professional Education brought by Law $11,892 / 2008$, the same law that redesigned the federal network of professional education then existing in Brazil. This work it is a bibliographical research, which aims to record the historical evolution regarding the creation of BETT the teaching career and the current reform of professional education.

KEYWORDS: Magisterium BETT, University Teaching, Professional Theaching Network. 


\section{INTRODUÇÃO}

O magistério do Ensino Básico, Técnico e Tecnológico (EBTT) foi criado em substituição à carreira anterior, a de magistério de $1^{\circ}$ e $2^{\circ} \mathrm{Graus,} \mathrm{porém} \mathrm{nem} \mathrm{todos} \mathrm{os} \mathrm{professores} \mathrm{dessa} \mathrm{carreira}$ aderiram à proposta do governo brasileiro, logo, atualmente coexistem as duas carreiras e atuam paralelamente, porém com pequenas diferenças, pois uma atua em magistério de $1^{\circ}$ e $2^{\circ}$ graus, ou seja, educação básica enquanto a nova carreira, de magistério EBTT tem permissão legal de atuação, na educação básica, técnica e tecnológica.

A carreira de magistério de $1^{\circ}$ e $2^{\circ}$ graus foi instituída nas antigas Escolas Técnicas Federais, Escolas Agrotécnicas Federais, Colégios Militares e Colégio Pedro II continuando nos Centros Federais de Educação Tecnológica (CEFETs). Na última instituição atuavam paralelamente professores do magistério de $1^{\circ}$ e $2^{\circ}$ graus e também do magistério superior, em função da oferta de ensino superior.

A partir da criação dessa nova carreira, os professores do magistério de $1^{\circ}$ e $2^{\circ}$ graus foram consultados quanto à possibilidade de migração para nova carreira, sob pena de ficarem estagnados, porque a carreira antiga seria extinta e consequentemente seus profissionais só receberiam reajustes salariais, por exemplo, se houvesse uma lei específica para aquela carreira. Os profissionais que migraram para nova carreira, a de professor EBTT, e àqueles que estavam ingressando na Rede Federal de Educação Tecnológica seriam regidos pela nova lei, porém sem nenhuma regulamentação.

O objetivo deste artigo é apresentar a evolução da carreira de magistério do Ensino Básico, Técnico e Tecnológico (EBTT) que é bastante recente tendo em vista que foi criada pela Lei No 11.784, de 22 de setembro de 2008, que dispõe sobre a reestruturação do Plano Geral de Cargos do Poder Executivo (PGPE), dentre eles cargos de Magistério do Ensino Básico, Técnico e Tecnológico (EBTT), foco principal deste artigo que foi regulamentada e reestruturada pela Lei No 12.772, de dezembro de 2012. Esse lei dispõe sobre a reestruturação do Plano de Carreiras de Cargos do Magistério Federal, entre elas o professor EBTT.

Além do foco principal, já mencionado, pretende-se discorrer sobre a expansão da rede federal de educação tecnológica, além da progressão, promoção ou aceleração do profissional do magistério EBTT, a qual foi criada para fins da formação de profissionais orientados para as metas de desenvolvimento do país.

Quanto à delimitação teórica, nossa análise será fundamentada nas leis que regem as duas carreiras do magistério, como: Lei № 11.784, de 22 de setembro de 2008 (BRASIL, 2008), que dispõe sobre a reestruturação do Plano Geral de Cargos do Poder Executivo (PGPE), do Plano de Carreira e Cargos de Magistério do Ensino Básico, Técnico e Tecnológico (EBTT), e do Plano de Carreira do Ensino Básico Federal; a Lei No 12.772, de dezembro de 2012 (BRASIL, 2012), que dispõe sobre a estruturação do Plano de Carreiras e Cargos de Magistério Federal; sobre o Plano de Carreira e Cargos de Magistério do Ensino Básico, Técnico e Tecnológico e sobre o Plano de Carreiras de Magistério do Ensino Básico Federal, de que trata a Lei no 11.784, de 22 de setembro de 2008; bem como o Decreto No 94.664, de 23 de julho de 1987 que Aprovou o Plano Único de Classificação e Retribuição de Cargos e Empregos do magistério de 10 e 2o Graus, Lei № 7.596, de 10 de abril de 1987 (BRASIL, 1987). 
A metodologia da pesquisa desenvolvida será de cunho teórico discursivo baseado em levantamento bibliográfico e acompanhamento das discussões atuais do Ministério de Planejamento e Gestão (MPOG) e pelos sindicatos da categoria a cerca do tema.

A justificativa é que a carreira é nova, com menos de sete anos de criação e, portanto, existem muitos pontos em aberto, ou seja, sem regulamentação ou com distorções em relação ao magistério superior. O impasse maior é que na carreira de magistério do EBTT, o profissional atua desde a Educação Básica, passando pelo Ensino Técnico e, abrangendo até o Ensino Superior Tecnológico e de Licenciaturas e, por isso, há muitos pontos de discussões por que é uma carreira cuja atuação não é só na Educação Básica e muito menos sua atuação é só no Ensino Superior. Por isso existem discussões no sentido de unificação das carreiras do EBTT e do Magistério Superior com o intuito de correção das distorções inclusive financeira entre as carreiras.

O presente artigo será organizado nas seguintes seções e subseções compostas pela introdução e contextualização histórica que definiu o problema, elaboraram os objetivos e a hipótese, delimitou-se a pesquisa nas suas dimensões espacial, temporal e teórica, em seguida serão abordados a criação dos Institutos Federais, regulamentação, estruturação e reestruturação do plano de carreira e cargos de magistério do ensino básico técnico e tecnológico (EBTT), progressão, promoção e aceleração da promoção no magistério do EBTT.

\section{CONTEXTUALIZAÇÃO HISTÓRICA DA REDE FEDERAL DE EDUCAÇÃO PROFISSIONAL NO BRASIL}

Para discorrer sobre a carreira de magistério do EBTT é impossível desvincular-se da contextualização histórica da Rede Federal de Educação Profissional, Científica e Tecnológica, não referenciada por essa nomenclatura, mas sua história começou em 1909, quando o então Presidente da República, Nilo Peçanha, criou 19 escolas de Aprendizes e Artífices que, mais tarde, evoluiu para Escolas Técnicas Federais, mas ainda voltadas para ensino técnico profissional, a nível de ensino médio.

Em meados de 1978, foi sancionada a Lei $N^{\circ} 6.545$, de junho de 1978 , transformando algumas das Escolas Técnicas Federais e/ou Escolas Agrotécnicas Federais existentes no Brasil, em Centros Federais de Educação Profissional e Tecnológica (CEFETs), instituições com autonomia administrativa, patrimonial, financeira, didático-pedagógica e disciplinar, ou seja, transformaramnas em autarquias federais, como respostas às demandas por formações profissionais em decorrência do desenvolvimento econômico estabelecido no país no final da década de 1970 e início de 1980. Com esse novo cenário econômico e produtivo se estabeleceu o desenvolvimento de novas tecnologias agregadas à produção e à prestação de serviços. Para atender essa demanda, as instituições de educação profissional buscaram diversificar programas e cursos para elevar os níveis de qualidade de suas ofertas.

Quando da transformação em CEFETs apenas três instituições foram transformadas inicialmente e deram origem ao CEFET-PR, ao CEFET-MG e ao CEFET-RJ (MANFREDI, 2002), que perduraram por mais de uma década, até 1994, quando foi sancionada a Lei № 8.948, de 8 de dezembro, que estabeleceu a transformação gradativa das Escolas Técnicas e Agrotécnicas Federais em CEFETs. Nesse ínterim, algumas Escolas Técnicas e Agrotécnicas Federais foram pleiteando sua ascensão a essa nova categoria, dentre elas a Escola Técnica Federal do Maranhão, 
tornando-se CEFET-MA em 1989, em decorrência do maranhense José Sarney ter assumido a Presidência do Brasil, no período de 15 de março de 1985 a 15 de março de 1990.

Nessa configuração, os CEFETs, eram responsáveis por ofertar educação profissional, por meio de seus diferentes cursos e programas, inclusive cursos superiores vinculados à área tecnológica e até mesmo cursos de pós-graduação lato e stricto sensu, além do ensino médio. Por ter essa diversidade de níveis de ensino, mantinham em seus quadros, professores da carreira de magistério de 1 으 e 2 o graus e da carreira de magistério de ensino superior.

Até dezembro de 2008 a rede era composta por 31 CEFETs, 75 Unidades Descentralizadas de Ensino (UNEDs) criadas por expansões ocorridas nas décadas de 1980 e 1990, 39 Escolas Agrotécnicas (EAFs), 7 Escolas Técnicas Federais (ETFs) e 8 Escolas vinculadas a universidades, os colégios universitários (COLUNs), mas a partir de 29 de dezembro de 2008, quase todas essas instituições, com exceção dos Centros Federais de Educação Tecnológica Celso Suckow da Fonseca - CEFET-RJ e de Minas Gerais - CEFET-MG, algumas Escolas Técnicas Vinculadas às Universidades Federais e do Colégio Pedro II, as demais unificaram-se e passaram a formar os Institutos Federais de Educação, Ciência e Tecnologia, ou simplesmente, Institutos Federais (IFs), (BRASIL, 2008). Estavam criados então, os IFs.

Com iminente criação dos Institutos Federais criou-se também a Rede Federal de Educação Tecnológica vinculada ao Ministério da Educação formalizada pela Lei № 11.892, de 29 de dezembro de 2008 (BRASIL, 2008), que instituiu a Rede Federal de Educação Profissional, Científica e Tecnológica, cria os Institutos Federais de Educação, Ciência e Tecnologia, e dá outras providências. Essas novas instituições de ensino técnicos criadas espelhou-se em centros de tecnologias nacionais, porque o termo tecnologia é definido "como a aplicação prática das ciências (ciência aplicada) objetivando a solução de problemas" (VARGAS, 1994), que pode ter seu significado ampliado incorporando outras dimensões. Por exemplo, para Ruy Gama, "a tecnologia moderna é a ciência do trabalho produtivo" (GAMA, 1986).

Com a criação dos IFs, as UNEDs, muitas EAFs e alguns COLUNs passaram a categoria de Câmpus e suas estruturas acadêmicas transformaram-se sendo criadas as pró-reitorias e uma reitoria para cada instituto federal criado. Os IFs passaram a ter natureza jurídica de autarquia, detentoras de autonomia administrativa, patrimonial, financeira, didático-pedagógica e disciplinar. Os câmpus passaram a ter uma estrutura com uma Direção Geral (DRG), uma Direção de Desenvolvimento de Ensino (DDE) e uma Direção de Planejamento e Gestão (DPG).

Com a criação dos IFs veio também sua expansão e nessa nova configuração todos seus câmpus deveriam ofertar cursos superiores em licenciaturas plenas e/ou tecnologia. Isso acarretou uma demanda de contratações de profissionais do magistério e administrativos que gerou problemas, como a criação da nova carreira do magistério do EBTT, tendo em vista que a existente não supriria tais necessidades, pois teriam de contratar novos professores de ensino médio técnico para ministrar aulas nos cursos profissionalizantes, ou seja, professores de $1^{\circ}$ e $2^{\circ}$ graus e também outros professores da carreira de magistério superior para ministrar aulas em nível de graduação para os cursos licenciaturas, tecnólogos e pós-graduações lato e stricto sensu.

A saída mais viável para essa problemática foi então, transformar a carreira anterior, de magistério de $1^{\circ}$ e $2^{\circ}$ graus, que só poderia ministrar aulas na Educação Básica em um professor de Ensino Básico, Técnico e Tecnológico com possibilidades de ministrar aulas tanto na Educação Básica (Ensino Fundamental e Médio) quanto no Ensino Superior (Licenciaturas e Tecnólogos), 
porém os profissionais que já estavam na rede eram os mesmos que só ministravam aulas de Educação Básica. A partir daquele momento, esse profissional começou a realizar ações no sentido de qualificar-se para melhorar sua qualidade técnica e prestação de um ensino de qualidade.

A carreira de Professor do EBTT está estruturada por classes, sendo composta pelas classes: D I, D II, D III, D IV e Professor Titular. O ingresso na carreira se dá por concursos de provas e títulos e o ingressante inicia no nível 1 da Classe D I. Quando da criação da carreira cada classe era composta por quatro níveis, no entanto, após amplas discussões em função da categoria achar que levaria muito tempo para se atingir o topo, ou seja, o último nível da última classe, então, sindicatos e governo entraram em entendimento e suprimiu-se dois níveis das duas primeiras classes ficando portanto, tais classes com apenas dois níveis. Outro ponto de discussão que causou muita polêmica antes da regulamentação, foi o tempo de serviço para progressão horizontal, ou seja, de um nível ou referência para outra imediatamente superior dentro da mesma classe. Alguns institutos entendiam que seria um ano e meio, outros que seriam dois anos. Assim, no início, alguns professores progrediram com um ano e meio, mas posteriormente todos passaram a progredir de dois em dois anos, conforme ocorre com os professores do magistério do ensino superior e que se encontra regulamentado atualmente.

A educação profissional, no Brasil, teve na sua origem a ideia de atender as classes menos favorecidas, porém, com o desenvolvimento do país, a mão de obra qualificada tornou-se cada vez mais valorizada. De acordo com (MOLL, 2010), a educação profissional e tecnológica é um tema que, desde os meados dos anos de 1990, vem ganhando destaque na pesquisa educacional no Brasil, face à proposição e implementação de um amplo conjunto de reformas educacionais e ao estabelecimento de diversas políticas públicas e programas governamentais relacionados à temática.

Dentre as diversas ações do governo federal em relação a essa modalidade de educação, encontra-se a expansão da rede federal de educação profissional, científica e tecnológica, que, desde 2003, tem evoluído tanto de forma quantitativa como qualitativa com autorização de criação IFs pela Lei no 11.892, de 29 de dezembro de 2008.

\section{ESTRUTURAÇÃO DO PLANO DE CARREIRA E CARGOS DE MAGISTÉRIO DO ENSINO BÁSICO TÉCNICO E TECNOLÓGICO (EBTT)}

A carreira de magistério de EBTT desde sua criação até a data de 10 de março de 2013 (entrada em vigor), a partir de sua estruturação pela promulgação da Lei 12.772, de 28 de dezembro de 2012, estava sem regulamentação levando a entendimentos errôneos. A Lei supracitada dispõe sobre a estruturação do Plano de Carreiras e Cargos de Magistério Federal; sobre o Plano de Carreira e Cargos de Magistério do Ensino Básico, Técnico e Tecnológico e sobre o Plano de Carreiras de Magistério do Ensino Básico Federal, de que trata a Lei no 11.784, de 22 de setembro de 2008. De acordo com Lei foi estruturado, a partir de 1ㅇ de março de 2013, o Plano de Carreiras e Cargos de Magistério Federal, composta por quatro Carreiras e cargos, dentre as quais está a Carreira de Magistério do Ensino Básico, Técnico e Tecnológico, composta pelos cargos de provimento efetivo de Professor do Ensino Básico, Técnico e Tecnológico, de que trata a Lei no 11.784 , de 22 de setembro de 2008; 
Essa Carreira de Magistério EBTT é composta pelas seguintes classes: D I, D II, D III, D IV e Titular. Sendo esta última classe criada pela Medida Provisória no 614, de 14 de maio de 2013, convertida na Lei no 12.863, de 24 de setembro de 2013.

As classes D I e D II tinham inicialmente 4 níveis, no entanto, com a reformulação ocorrida no ano 2012 em função de discussões ocorridas entre sindicatos da categoria e governo, em período de greve, chegando ao entendimento e as referidas classes passaram a ter apenas dois níveis (1 e 2). Já as demais classes D III e D IV continuaram desde sua criação com 4 níveis (1, 2, 3 e 4); com exceção da classe Titular, que foi criada posteriormente e com apenas um único nível.

A Carreira de Magistério do Ensino Básico, Técnico e Tecnológico deve ser exercida por profissionais habilitados em atividades acadêmicas próprias do pessoal docente no âmbito da educação básica e da educação profissional e tecnológica, de acordo com o disposto nas Leis no 9.394, de 20 de dezembro de 1996 e no 11.892, de 29 de dezembro de 2008. A referida Carreira de Magistério de EBTT e o Cargo Isolado de Professor Titular de EBTT, de que tratam os incisos I e II do caput do art. 106 da Lei no 11.784, de 2008, passaram a pertencer ao Plano de Carreiras e Cargos de Magistério Federal, na forma desta lei, deixando de pertencer ao Plano de Carreiras de que trata o art. 105 da Lei no 11.784 , de 2008.

O ingresso nos cargos de provimento efetivo de Professor da Carreira de Magistério do Ensino Básico, Técnico e Tecnológico e da Carreira do Magistério do Ensino Básico Federal ocorrerá sempre no Nível 1 da Classe D I, mediante aprovação em concurso público de provas ou de provas e títulos.

Para ser nomeado professor do EBTT, o profissional habilitado em concurso público deverá comprovar diploma de curso superior em nível de graduação. O concurso público poderá ser organizado em etapas, conforme dispuser o edital de abertura do certame. O edital do concurso público estabelecerá as características de cada etapa do concurso público e os critérios eliminatórios e classificatórios do certame.

O professor do magistério de EBTT só terá direito a aceleração da promoção após decorrido a avaliação de estágio probatório, que ocorrerá após 3 anos de efetivo exercício de suas funções no cargo. O processo de avaliação de desempenho para fins de progressão funcional e de promoção foram estabelecidas pelo Ministério da Educação pela Portaria № 554, de 20 de Junho de 2013, (Brasil, 2013), que estabelece as diretrizes gerais para o processo de avaliação de desempenho para fins de progressão e de promoção dos servidores pertencentes ao Plano de Carreiras e Cargos de Magistério Federal das Instituições Federais de Ensino vinculadas ao Ministério da Educação, de que trata o capitulo III da Lei no 12.772, de 28 de dezembro de 2013 e deverão contemplar as atividades de ensino, pesquisa, extensão e gestão, cabendo aos conselhos competentes no âmbito de cada Instituição Federal de Ensino regulamentar os procedimentos do referido processo.

O processo de avaliação para acesso à Classe Titular será realizado por comissão especial composta, no mínimo, por $75 \%$ (setenta e cinco por cento) de profissionais externos à IFE, e será objeto de regulamentação por ato do Ministro de Estado da Educação.

Os cursos de mestrado e doutorado, para fins de progressão, promoção e aceleração de promoção só serão considerados se forem credenciados pelo Conselho Federal de Educação e, quando realizados no exterior, deverão ser revalidados por instituição nacional competente. 


\section{RESULTADOS}

No governo, do sociólogo Fernando Henrique Cardoso (FHC) implementou-se políticas públicas direcionadas ao ensino profissional, seguindo os ditames neoliberais de enxugamento da máquina pública e de enfrentamento prioritário das questões econômicas do país, em detrimento das sociais. Nesse período, se cogitou até mesmo a possibilidade de passar os CEFETs, Escolas Agrotécnicas, Escolas Técnicas Federais e os Colégios Técnicos vinculados às universidades federais às expensas estaduais.

Nesse período a atual LDB entrou em vigor e nessa oportunidade o governo implementou, de fato, uma política de separação entre o ensino propedêutico e a educação profissional, a qual foi reforçada pela Portaria MEC no 646, de 14 de maio de 1997, que regulamentou a implantação do disposto nos Arts. 39 a 42 da Lei de Diretrizes e Bases da Educação Nacional (LDB) limitando a oferta do ensino médio ao máximo de $50 \%$ de suas matrículas nas instituições federais de ensino, "induzindo a abertura de cursos exclusivamente profissionalizantes." (ORTIGARA; GANZELI, 2011, p. 05).

Ainda no governo FHC, o Brasil apresentou um histórico de desregulamentação intencional no campo da formação docente para a educação profissional e isto, aliado à política neoliberal de expansão da Educação Profissional e Tecnológica (EPT) com o mínimo custo financeiro possível, terminou criando e até mesmo agravando ainda mais uma crise de identidade dos docentes de EBTT.

Assim, a ausência de formação específica para os professores das instituições federais de ensino que atuavam na educação profissional contribuiu para a crise de identidade que assolava esta categoria docente.

Com o fim da era FHC e início do governo Lula, retomou-se a discussão sobre a separação entre ensino médio e ensino profissional implementado pelo Decreto №. 2.208, de 17 de abril de 1997, momento no qual se passou a rediscutir a importância da educação politécnica.

De acordo com (LIBÂNEO, OLIVEIRA E TOSCHI, 2009), "a política educacional adotada no Governo FHC foi concebida de acordo com a proposta do neoliberalismo e assumiu dimensões tanto centralizadoras como descentralizadoras." No entanto, a descentralização não apareceu como resultado de maior participação da sociedade, uma vez que as ações realizadas não foram fruto de consultas aos diversos setores sociais, tais como pesquisadores, universidades, professores, sindicatos, associações e outros, mas, ao invés, surgiram de decisão preparada desde a campanha eleitoral.

Ressalta-se, ainda, que a maioria das Escolas Técnicas vinculadas às Universidades Federais, ou seja, os COLUNs, responsáveis pela oferta do ensino médio de nível técnico, foi incorporada a estas últimas, ocasionando a inserção de professores do ensino profissional (magistério EBTT) dentro do quadro funcional de instituições de nível superior, cuja maior parte do corpo docente é composta por professores integrantes da carreira do Magistério Superior, sendo mais um fator que desencadeou na crise de identidade daqueles profissionais.

É importante relembrar que a evolução da carreira de magistério do EBTT ocorreu em função da sanção da Lei no 11.784, de 22 de setembro de 2008, que, dentre outras carreiras ocorreram também a reestruturação do Plano Geral de Cargos do Poder Executivo - PGPE e do 
Plano de Carreira e Cargos de Magistério do Ensino Básico, Técnico e Tecnológico e do Plano de Carreira do Ensino Básico Federal; composta pelas carreiras de nível superior do Quadro de Pessoal das Instituições Federais de Ensino, subordinadas ou vinculadas ao Ministério da Educação, que integram a Carreira de Magistério de 10 e 20 Graus, de tal modo que os profissionais ocupantes desses cargos foram convidados a migrarem espontaneamente para a nova Carreira de Magistério do EBTT, sob pena de ficarem em uma carreira que seria extinta ou estagnada. Isso ocorreria com a finalidade de suprir a incongruência que se instalou com a transformação das Escolas Técnicas Federais (ETFs) e Escolas Agrotécnicas Federais (EAFs) em CEFETs surgindo a necessidade de duas carreiras de magistério federal atuarem dentro da mesma instituição, a de magistério de $1^{\circ}$ e $2^{\circ}$ Graus e a de Magistério Superior.

A referida incompatibilidade entre as carreiras se justifica pelo fato de existirem professores pertencentes aos quadros funcionais das antigas ETFs e EAFs que ministravam aulas apenas no 10 e 20 Graus e, com a transformação em CEFETs, passaram a ministrar aulas também no ensino superior, conforme determinação do Art. $4^{\circ}$ de Decreto no 5.224, de $1^{\circ}$ de outubro de 2004, que dispõe sobre a organização dos Centros Federais de Educação Tecnológica (CEFETs) e dá outras providências.

Portanto, o fato do profissional integrante da carreira de Magistério do EBTT ser professor habilitado para ministrar aulas no ensino médio, no ensino técnico e no tecnológico (educação profissional de nível superior) constitui mais um fundamento para que o mesmo seja submetido à mesma regulamentação destinada aos professores da carreira do Magistério Superior, quanto ao seu regime de trabalho e divisão da carga horária.

No entanto há o entendimento do governo que diz que a diferenciação entre as carreiras de Magistério do EBTT e Superior, em função das peculiaridades existentes entre os institutos e as universidades, ou seja, as finalidades de cada instituição é diferente.

Mesmo que não se cogitasse a criação da Lei no 12.772, de 28 de dezembro de 2012, poderia se afirmar que o professor integrante da Carreira do Ensino Básico, Técnico e Tecnológico ministra aulas também no ensino profissional tecnológico (superior) e por que razão o disciplinamento legal da divisão de carga horária de trabalho deveria ser o mesmo que é dispensado ao professor integrante da carreira do Magistério Superior, conforme artigo 10, §10 da Portaria do MEC no 475, de 26 de agosto de 1987.

No entanto, na atual conjuntura a carreira de Magistério do EBTT teve uns ganhos mais vantajosos em função das discussões e entendimentos ocorridos na greve de 2012 e que começaram a ser regulamentados e implementados em 2013, como a criação e implantação dos Reconhecimentos de Saberes e Competências e que os profissionais do MS não foram contemplados criando assim um impasse que dificilmente levará a unificação das duas carreiras de magistério federal.

Outro impasse que há dentro dos institutos é que após a criação dos CEFETs com atribuições para oferecer educação superior foram criados a carreira de MS dentro de suas estruturas para suprir as necessidades dos cursos superiores de tecnologias. Sendo assim, após a criação dos institutos e da carreira de magistério do EBTT, ainda continuam esses professores do MS que não têm direito aos mesmos benefícios, nem mesmo de concorrer em editais de remoção, em função das carreiras não terem a mesma natureza, o que a essa discussão de unificação das carreiras. 
Assim, os profissionais do magistério do EBTT querem o direito de ter de assinar folhas de ponto, como ocorrem nas universidades e estas por sua vez querem ter direito ao RSC. Paralelamente a tudo isso, os profissionais pertencentes ao corpo técnico administrativo de ensino superior querem também ter o direito à cobiçada RSC.

\title{
5 ANÁLISE E DISCUSSÃO DOS RESULTADOS
}

As discussões envolvendo as carreiras de magistério federal de EBTT e Superior, de um lado está o governo, de outro o sindicato representante da carreira de Magistério Superior (MS), o Sindicato Nacional de Docentes das Instituições de Ensino Superior (ANDES) e ainda de outro, o sindicato representante dos professores de EBTT, a Federação de Sindicatos de Professores de Instituições de Ensino Superior (PROIFES Federação) e o Sindicato Nacional do Servidores Federais de Educação Básica, Profissional e Tecnológica (Sinasefe). Para o governo, há uma diferenciação entre as carreiras de EBTT e MS, porque existem peculiaridades entre os institutos e as universidades e por isso exigem tratamento diferente. Para o PROIFES, a unificação das duas carreiras é considerada maléfica, tendo em vista que nas universidades que possuem MS, cerca de $80 \%$ dos docentes possuem doutorado, apresentando impactos positivos, entretanto, para o EBTT, carreira na qual apenas cerca de $7 \%$ dos docentes são doutores, o resultado seria desastroso. 0 Andes defende a tese de carreira única. Pacheco (2010) retrata ainda algumas peculiaridades dos IFs, corroborando com o que defende o governo e alguns sindicatos, que a nova organização acadêmica, singular aos Institutos Federais (IFs), aponta para a ruptura da reprodução de modelos externos e toma a inovação a partir da relação entre o ensino técnico e o científico, articulando trabalho, ciência e cultura na perspectiva da emancipação humana.

\begin{abstract}
Na proposta dos Institutos Federais, agregar à formação acadêmica a preparação para o trabalho (compreendendo-o em seu sentido histórico, mas sem deixar de firmar o seu sentido ontológico) e discutir os princípios das tecnologias a ele concernentes dão luz a elementos essenciais para a definição de um propósito específico para a estrutura curricular da educação profissional e tecnológica. 0 que se propõem é uma formação contextualizada, banhada de conhecimentos, princípios e valores que potencializam a ação humana na busca de caminhos de vida mais dignos.
\end{abstract}

Assim, derrubar as barreiras entre o ensino técnico e o científico, articulando trabalho, ciência e cultura na perspectiva da emancipação humana, é um dos objetivos basilares dos Institutos. Sua orientação pedagógica deve recusar o conhecimento exclusivamente enciclopédico, assentando-se no pensamento analítico, buscando uma formação profissional mais abrangente e flexível, com menos ênfase na formação para ofícios e mais na compreensão do mundo do trabalho e em uma participação qualitativamente superior neste. Um profissionalizar-se mais amplo, que abra infinitas possibilidades de reinventar-se no mundo e para o mundo, princípios estes válidos, inclusive, para as engenharias e licenciaturas. (PACHECO, 2010, p. 10)

Para a parte que defende as duas carreiras, considerou-se uma conquista histórica que consolidou o acordo de 2008 entre sindicatos e o governo levando à criação da carreira de Magistério de Ensino Básico, Técnico e Tecnológico - EBTT. Segundo esta visão, o acordo de criação 
da nova carreira de magistério garantiu definitivamente a equiparação estrutural e salarial entre as carreiras de EBTT e do Magistério Superior.

Com a aprovação da lei que criou a carreira de magistério do EBTT, em 2008, as carreiras do magistério federal: EBTT e MS se aproximaram, pois as classes D-I, D-II e D-III equivalentes às classes de professor Auxiliar, professor Assistente e professor Adjunto, respectivamente, do Magistério Superior. A classe D-IV tem um único nível e a classe D-V tem 3 níveis e teriam equivalência à carreira do MS se considerarmos que a D-IV equivaleria ao primeiro nível da classe Associado e a classe D-V aos outros níveis da classe de professor Associado do MS.

Em 2012, com a aprovação da lei que regulamentou a carreira do EBTT, Lei no 12.772 , de 28.12.2012, as carreiras do EBTT e do MS tornaram-se equivalentes. Houve uma mudança no magistério do EBTT com a unificação das classes D-IV e D-V transformando-se em apenas classe DV com 4 níveis e por fim foi criado a classe de Titular. Portanto, ficou consolidado em lei a equivalência salarial e estrutural entre os professores do magistério federal. Nesta formulação, todas as vantagens e direitos estão garantidas para ambas as carreiras. De maneira geral a transição foi muito vantajosa para os docentes do EBTT.

Além disso, criou-se o Reconhecimento de Saberes e Competências (RSC) em que um docente do magistério EBTT pode, mediante análise de seu conhecimento, experiência e competência, adquirir o direito de receber a retribuição por titulação (RT) de um nível acima do seu. Por exemplo, o professor graduado pode requerer a RT de especialista; um especialista poderá requerer a RT de mestre e um mestre poderá requerer a RT de doutor. Quando o docente obtém um novo título, perde o RSC que possuía e adquire o direito pleiteá-lo novamente para o título subsequente.

\section{CONSIDERAÇÕES FINAIS}

Fazendo um breve retrospecto histórico da experiência vivida na fase de criação dos institutos federais e da carreira de magistério do EBTT, pode-se afirmar que muitos dos objetivos da implantação da nova carreira de magistério federal e da reestruturação dos novos planos de carreiras foram alcançados, especialmente aqueles relacionados à equiparação com o magistério superior, em razão das similaridades das funções.

Com essa equiparação estrutural e salarial, os novos profissionais estão procurando qualificar-se, aumentando consequentemente o número de servidores que têm buscado a elevação do nível de escolaridade após a reestruturação das carreiras.

Com expansão da rede federal observou-se, ainda, um aumento e uma renovação dos quadros de pessoal, por meio da oferta de mais vagas em concursos públicos realizados, não só para o magistério como também para pessoal técnico administrativo, com elevada procura após a reestruturação das carreiras. Todos esses fatores favorecem o aumento da efetividade e da qualidade dos serviços públicos.

Os municípios contemplados por algum campus, também foram beneficiados não só a injeção de recursos financeiros, bem como seus habitantes passaram a receber uma educação de tecnológica de fronteira e também a aprovação de seus habitantes nos concursos realizados. 
Os planos de carreiras devem ser considerados como incentivo para a melhoria do desempenho e da qualificação do servidor, refletindo diretamente na elevação da qualidade dos serviços públicos. Daí a necessidade, após a estruturação e reestruturação do plano de carreiras, de uma gestão efetiva e mais célere na implementação dos benefícios (progressões, promoções, aceleração de promoções e reconhecimento de saberes e competências), bem como uma interface permanente com a criação das comissões permanentes de pessoal docente (CPPD) locais e central para melhorar o fluxo das avaliações de desempenho.

\section{REFERÊNCIAS BIBLIOGRÁFICAS}

1. BRASIL, Lei № 11.784, de 22 de setembro de 2008. Dispõe sobre a reestruturação do Plano Geral de Cargos do Poder Executivo - PGPE, de que trata a Lei no 11.357, de 19 de outubro de 2006, do Plano Especial de Cargos da Cultura, de que trata a Lei № 11.233, de 22 de dezembro de 2005, do Plano de Carreira dos Cargos Técnico-Administrativos em Educação, de que trata a Lei no 11.091, de 12 de janeiro de 2005, da Carreira de Magistério Superior, de que trata a Lei no 7.596, de 10 de abril de 1987, do Plano de Carreira e Cargos de Magistério do Ensino Básico, Técnico e Tecnológico, e do Plano de Carreira do Ensino Básico Federal; institui sistemática para avaliação de desempenho dos servidores da administração pública federal direta, autárquica e fundacional. Brasília, 2008.

$2 . \quad$. Lei № 12.772, de 28 de dezembro de 2012. Dispõe sobre a estruturação do Plano de Carreiras e Cargos de Magistério Federal; sobre a Carreira do Magistério Superior, de que trata a Lei no 7.596, de 10 de abril de 1987; sobre o Plano de Carreira e Cargos de Magistério do Ensino Básico, Técnico e Tecnológico e sobre o Plano de Carreiras de Magistério do Ensino Básico Federal, de que trata a Lei no 11.784, de 22 de setembro de 2008; altera remuneração do Plano de Cargos Técnico-Administrativos em Educação e dá outras providências. Brasília, 2012.

3. Lei № 11.892, de 29 de dezembro de 2008. Institui a Rede Federal de Educação Profissional, Científica e Tecnológica, cria os Institutos Federais de Educação, Ciência e Tecnologia, e dá outras providências. Brasília, 2008.

4.

Decreto $\mathbf{N}^{\circ}$ 94.664, de 23 de julho de 1987. Aprova o Plano Único de Classificação e Retribuição de Cargos e Empregos de que trata a Lei no 7.596, de 10 de abril de 1987.

5. VARGA, Milton. O Início de Pesquisa Tecnológica no Brasil. São Paulo: UNESP-CEFET SP, 1994 b. Cap.2, p 211-224.

6. GAMA, Ruy. A Tecnologia do Trabalho na História. São Paulo: Nobel, EDUSP, 1986.

$7 . \quad$. Decreto № 7.566, de 23 de setembro de 1909. Créa nas capitaes dos Estados da Escolas de Aprendizes Artífices, para o ensino profissional primário e gratuito. Rio de Janeiro. 1909.

8. MOLL, Jaqueline. Educação Profissional e Tecnológica no Brasil Contemporâneo - Desafios, Tensões e Possibilidades. Artmed. Porto Alegre, 2010.

9. Decreto no 2.208, de 17 de abril de 1997. Regulamenta o $§ 2$. 2 do art. 36 e os arts. 39 a 42 da Lei no 9.394, de 20 de dezembro de 1996, que estabelece as diretrizes e bases da educação nacional. Brasília. 1997.

10. ORTIGARA, Claudino; GANZELI, Pedro. Regulação nas Políticas Para a Educação Profissional 
nos Governos FHC e Lula: trabalho e cidadania. 2011.

11. .Lei de Diretrizes e Bases da Educação Nacional (LDB). Lei no 9.394, de 20 de dezembro de 1996. Estabelece as diretrizes e bases da educação nacional. Brasília. 1996.

12. LIBÂNEO, José Carlos; OLIVEIRA, João Ferreira de; TOSCHI, Mirza Seabra. Educação Escolar: políticas, estruturas e organização. São Paulo: Cortez, 2009.

13. ANDES. Carreira em debate: valorização do professor ou retirada de conquistas? Brasília: ANDES-SN, 2010. Disponível em: <http://www.adufu.org.br/admin/uploads/noticias/files/ ANDES_-_cartilha_carreira.PDF>. Acesso em: 05 de maio de 2015.

14. L_Lei no 12.863, de 24 de setembro de 2013. Altera a Lei no 12.772, de 28 de dezembro de 2012, que dispõe sobre a estruturação do Plano de Carreiras e Cargos de Magistério Federal; altera as Leis nos 11.526, de 4 de outubro de 2007, 8.958, de 20 de dezembro de $1994,11.892$, de 29 de dezembro de 2008, 12.513, de 26 de outubro de 2011, 9.532, de 10 de dezembro de 1997, 91, de 28 de agosto de 1935, e 12.101, de 27 de novembro de 2009; revoga dispositivo da Lei no 12.550, de 15 de dezembro de 2011; e dá outras providências. Brasília DF. 2013.

15. Resolução $\mathbf{n}^{\circ} \mathbf{0 4 0}$, de 04 de agosto de 2014. Estabelece critérios e procedimentos para avaliação de desempenho acadêmico e para verificação quanto ao cumprimento dos requisitos de titulação necessários para progressão e promoção funcionais por desempenho acadêmico e por titulação dos servidores das carreiras do magistério federal do Instituto Federal de Educação, Ciência e Tecnologia do Maranhão, conforme os artigos $12, \S 4^{\circ}, 14$, $\S 4^{\circ}$, da Lei $n^{\circ}$ 12.772, de 28 de dezembro de 2012, com as alterações da Medida Provisória $n^{\circ}$ 614, de 18 de maio de 2013 e da Lei $n^{\circ}$ 12.863, de 24 de setembro de 2013, portaria do Ministro da Educação $n^{\circ}$ 554, de 20 de junho de 2013, republicada em 29 de julho de 2013.. São Luís - MA. 2014.

16.

.Portaria MEC № 554, de 20 de junho de 2013. Estabelece as diretrizes gerais para o processo de avaliação de desempenho para fins de progressão e de promoção dos servidores pertencentes ao Plano de Carreiras e Cargos de Magistério Federal das Instituições Federais de Ensino vinculadas ao Ministério da Educação, de que trata o capitulo III da Lei no 12.772, de 28 de dezembro de 2013. Brasília, 2013.

17.

.Decreto № 5.224, de $\mathbf{1}^{\circ}$ de outubro de 2004. Dispõe sobre a organização dos Centros Federais de Educação Tecnológica e dá outras providências. Brasília, 2004.

18. _. Portaria do MEC № 475, de 26 de agosto de 1987. Expede Normas Complementares para a execução do Decreto $n^{\circ}$ 94.664, de 23 de julho de 1987. Brasília, 1987.

19. PACHECO, Eliezer. Os Institutos Federais: uma revolução na educação profissional e tecnológica. Brasília: MEC/SETEC, 2010. 